\title{
Resistance to DNA-damaging treatment in non-small cell lung cancer tumor-initiating cells involves reduced DNA-PKJATM activation and diminished cell cycle arrest
}

\author{
L Lundholm ${ }^{1,2}$, P Hååg ${ }^{1,2}$, D Zong ${ }^{1}$, T Juntti ${ }^{1}$, B Mörk ${ }^{1}$, R Lewensohn ${ }^{1}$ and K Viktorsson ${ }^{\star, 1}$
}

Increasing evidence suggests that tumor-initiating cells (TICs), also called cancer stem cells, are partly responsible for resistance to DNA-damaging treatment. Here we addressed if such a phenotype may contribute to radio- and cisplatin resistance in non-small cell lung cancer (NSCLC). We showed that four out of eight NSCLC cell lines (H125, A549, H1299 and H23) possess sphere-forming capacity when cultured in stem cell media and three of these display elevated levels of CD133. Indeed, sphere-forming NSCLC cells, hereafter called TICs, showed a reduced apoptotic response and increased survival after irradiation (IR), as compared with the corresponding bulk cell population. Decreased cytotoxicity and apoptotic signaling manifested by diminished poly (ADPribose) polymerase (PARP) cleavage and caspase 3 activity was also evident in TICs after cisplatin treatment. Neither radiation nor cisplatin resistance was due to quiescence as H125 TICs proliferated at a rate comparable to bulk cells. However, TICs displayed less pronounced G2 cell cycle arrest and S/G2-phase block after IR and cisplatin, respectively. Additionally, we confirmed a cisplatin-refractory phenotype of H125 TICs in vivo in a mouse xenograft model. We further examined TICs for altered expression or activation of DNA damage repair proteins as a way to explain their increased radio- and/or chemotherapy resistance. Indeed, we found that TICs exhibited increased basal $\gamma \mathrm{H} 2 \mathrm{AX}$ (H2A histone family, member X) expression and diminished DNA damageinduced phosphorylation of DNA-dependent protein kinase (DNA-PK), ataxia telangiectasia-mutated (ATM), Krüppel-associated protein 1 (KAP1) and monoubiquitination of Fanconi anemia, complementation group D2 (FANCD2). As a proof of principle, ATM inhibition in bulk cells increased their cisplatin resistance, as demonstrated by reduced PARP cleavage. In conclusion, we show that reduced apoptotic response, altered DNA repair signaling and cell cycle perturbations in NSCLC TICs are possible factors contributing to their therapy resistance, which may be exploited for DNA damage-sensitizing purposes.

Cell Death and Disease (2013) 4, e478; doi:10.1038/cddis.2012.211; published online 31 January 2013

Subject Category: Cancer

Lung cancers (LCs) are among the most common human malignancies worldwide. ${ }^{1}$ Despite the use of aggressive multimodal chemo- and radiotherapy (CT/RT), the 5-year survival of LC patients remain as low as $15 \%{ }^{2}$ Resistance to $\mathrm{CT} / \mathrm{RT}$ is a commonly encountered problem in both treatmentnaive LC patients and during the course of CT/RT. ${ }^{2}$ Yet, the molecular mechanisms underlying $\mathrm{CT} / \mathrm{RT}$ refractoriness are complex and still largely undefined. Identification of such mechanisms could reveal crucial tumor-specific aberrations that are amenable to targeted intervention, ${ }^{2}$ as well as generating biomarker profiles that will enable individualized therapy. ${ }^{3}$
Emerging evidence indicates the existence of a rare fraction of tumor cells endowed with properties characteristic of somatic/embryonic stem cells, cancer stem cells or, as hereafter called, tumor-initiating cells (TICs). ${ }^{4}$ TICs typically show elevated expression of the stem cell-associated markers CD133, SRY-related HMG-box 2 (Sox2), octamerbinding transcription factor 4 (Oct4) and Nanog, display high tumorigenic potential and have been associated with a CT/ RT-refractory phenotype. ${ }^{5-7}$ TICs can be enriched by surface marker expression or their ability to form spheres in culture, as demonstrated in different tumor types including non-small cell lung cancer (NSCLC) ${ }^{5,6,8}$ One of the most widely used

\footnotetext{
${ }^{1}$ Department of Oncology-Pathology, Karolinska Biomics Center, Karolinska Institutet and Karolinska University Hospital, Stockholm, Sweden

*Corresponding author: K Viktorsson, Department of Oncology-Pathology, Karolinska Biomics Center, Karolinska Institutet and Karolinska University Hospital, Z5:01, SE- 17176 Stockholm, Sweden. Tel: + 4685177 0177; Fax: + 4685177 1000; E-mail: Kristina.Viktorsson @ki.se

${ }^{2}$ These authors contributed equally to this work.

Keywords: lung cancer; tumor-initiating cells; resistance; radiation; chemotherapy; DNA repair

Abbreviations: ATM, ataxia telangiectasia-mutated; ATP7B, ATPase, $\mathrm{Cu}^{2+}$ transporting, $\beta$ polypeptide; AUC, area under the curve; Cdc25A, cell division cycle 25 homolog A; CFSE, carboxyfluorescein diacetate $\mathrm{N}$-succinimidyl ester; Chk2, checkpoint kinase 2; CT, chemotherapy; CTR1, copper transporter 1; DDR, DNA damage response; DNA-PKcs, DNA-dependent protein kinase, catalytic subunit; EDTA, ethylenediaminetetraacetic acid; FANCD2, Fanconi anemia, complementation group D2; Gy, Gray; H2AX, H2A histone family, member X; IR, irradiation; KAP1, Krüppel-associated protein 1; LC, lung cancer; MTT, 3-(4,5-dimethylthiazol-2-yl)-2,5-diphenyltetrazolium bromide; NSCLC, non-small cell lung cancer; Oct4, octamer-binding transcription factor 4; PARP, poly (ADP-ribose) polymerase; PBS, phosphate-buffered saline; RPMI, Roswell Park Memorial Institute; RT, radiotherapy; SCID, severe-combined immunodeficiency; SMC1, structural maintenance of chromosomes 1; Sox2, SRY-related HMG-box 2; TBP, TATA-binding protein; TICs, tumor-initiating cells

Received 19.7.12; revised 30.11.12; accepted 4.12.12; Edited by A Stephanou
} 
markers is CD133, a cell surface transmembrane glycoprotein that has been postulated as a useful marker for stem cells in a variety of normal and tumor tissues. ${ }^{8-10}$

Few cellular signaling networks that confer resistance to conventional CT/RT have been unequivocally demonstrated in TICs. Nevertheless, enhanced DNA repair capacity has been implicated as a likely cause of increased CT/RT resistance in this cell population in gliomas and breast cancer. ${ }^{11-13}$ With respect to NSCLC, few studies have addressed if a TIC phenotype contribute to DNA-damaging treatment resistance and if it involves altered DNA repair signaling. To address this issue, we cultured tumor spheres from a panel of LC cell lines. We show that this approach enabled enrichment of sphere-forming TICs with increased CD133 expression compared with bulk cells. The TICs were more resistant to RT- and cisplatin-induced cell death and show diminished apoptotic response in vitro and in vivo in mouse tumor xenografts. On the molecular level, our analyses of NSCLC TICs demonstrate aberrant DNA damage response (DDR) due to inadequate activation of ataxia telangiectasiamutated (ATM), DNA-dependent protein kinase, catalytic subunit (DNA-PKcs), Krüppel-associated protein 1 (KAP1) and Fanconi anemia, complementation group D2 (FANCD2), leading to compromised cell cycle checkpoints. As a proof of principle, ATM inhibition in bulk cells increased their cisplatin resistance, as demonstrated by reduced poly (ADP-ribose) polymerase (PARP) cleavage. This is the first report showing that reduced activation of DDR can contribute to CT/RT resistance in TICs. Such differences in DDR signaling between TICs and bulk NSCLC cells may reveal important targetable pathways and allow for novel combination regimen with the potential to improve therapeutic outcome of LC disease.

\section{Results}

NSCLC cell lines contain cells with sphere-forming capacity indicative of a tumor-initiating phenotype. A panel of eight NSCLC cell lines were cultured for 7-14 days under conditions favoring stem cell growth and analyzed for their sphere-forming capacity. Four formed spheres (A549, $\mathrm{H} 23, \mathrm{H} 1299$ and H125), while one cell line (U-1752) could grow in stem cell media despite a lack of sphere-forming capacity (Figure 1). The time required for sphere formation varied among the cell lines as A549, H23 and H1299 cells developed distinct large spheres after 7 days, while $\mathrm{H} 125$ spheres still had adherent clusters along with detached spheres.

\footnotetext{
Expression of stem cell markers are increased in TICs. Expression levels of stem cell markers were characterized in the sphere-forming NSCLC TICs after 7-14 days of culture in stem cell media. The CD133 protein was expressed in $4 \%$ of H125 TICs and $10 \%$ of A549 TICs, a clear enrichment compared with the corresponding bulk cells, arbitrarily set to $1 \%$ (Figure 2a). Accordingly, mRNA levels of CD133 were increased in TICs from H125, A549 and H1299 cells (Figure 2b). The stem cell markers Sox2, Nanog and Oct4 all displayed increased mRNA expression at day 14 in A549 and H1299 TICs, whereas only Sox2 was increased in H23
}

TICs (Figure 2c). By contrast, increased expression of these markers was not observed in H125 TICs.

NSCLC TICs display resistance to RT. In breast cancer, glioma and medulloblastoma tumor cells with a TIC phenotype are resistant to RT. ${ }^{14}$ Here we addressed if this also is evident for NSCLC TICs. As expected, irradiation (IR) resulted in a dose-dependent reduction in the clonogenicity of $\mathrm{H} 125$ bulk cells, in contrast to $\mathrm{H} 125 \mathrm{TICs}$, which were highly refractory to IR at 2 and $4 \mathrm{~Gy}$ and only sensitive to $8 \mathrm{~Gy}$ (Figures 3a and b). Similarly, A549 TICs were more resistant than A549 bulk cells to IR at 2, 4 and 8 Gy, even though A549 bulk cells were less sensitive than $\mathrm{H} 125$ bulk cells. The SF2 (surviving fraction at $2 \mathrm{~Gy}$ ) value was increased from 0.36 to 0.66 in $\mathrm{H} 125$, and 0.53 to 0.71 in A549 TICs compared with bulk cells.

NSCLC TICs are more resistant to cisplatin compared with bulk cells. We next examined if NSCLC TICs were more resistant to CT using cisplatin. Notably, H125 and A549 TICs were significantly more resistant to cisplatin treatment compared with bulk cells with a relative difference in cell viability of 24 and $29 \%$ at $1 \mu \mathrm{M}$ cisplatin, respectively $(P<0.05$; Figure $3 c)$. The area under the curve after cisplatin treatment was 1.5-fold higher in $\mathrm{H} 125 \mathrm{TICs}$ and 2.3-fold in A549 TICs. Transporter proteins may influence the intracellular concentration and response to cisplatin; ${ }^{15}$ however, equal mRNA expression of the major uptake transporter, copper transporter 1 (CTR1, SLC31A1 (solute carrier family 31 , member 1)) and only moderately increased levels of the efflux protein ATPase, $\mathrm{Cu}^{2+}$ transporting, $\beta$ polypeptide (ATP7B) were found in H125 TICs (Supplementary Figure 1A), indicating the lack of large differences in uptake or export of cisplatin. In addition, cisplatin adduct formation was comparable in bulk cells and TICs (cisplatin $40 \mu \mathrm{M}, 6 \mathrm{~h}$ and $10 \mu \mathrm{M}, 24 \mathrm{~h}$ ), hence ruling out inefficient drug accumulation as the main cause for the altered cisplatin sensitivity (Supplementary Figure 1B).

Increased RT/CT resistance in NSCLC TICs is not solely attributed to differences in proliferative capacity of TICs. Stem cells are known to be in a quiescent state and it has been assumed that TICs as their malignant counterpart may be similarly less proliferative, and hence not as susceptible to conventional CT and RT. ${ }^{16}$ However, few studies have experimentally addressed the cell cycle distribution of TICs after DNA damage, and for NSCLC no such data are at hand; therefore, proliferation rate and cell cycle distribution was assessed (Figure 4). As judged by the dilution of carboxyfluorescein diacetate $\mathrm{N}$-succinimidyl ester (CFSE)-associated fluorescence signals after $72 \mathrm{~h}$, untreated $\mathrm{H} 125 \mathrm{TICs}$ divided at the same rate, whereas A549 TICS proliferated at roughly one-third of the growth rate of their bulk cells (Figure 4a). While the growth of $\mathrm{H} 125$ and A549 bulk cells was reduced after IR and cisplatin treatment, the post-treatment proliferation of TICs showed no marked changes apart from a small reduction after the higher dose of cisplatin $(10 \mu \mathrm{M})$ in $\mathrm{H} 125$ TICs, further confirming the therapy-resistant phenotype shown in Figure 3. 

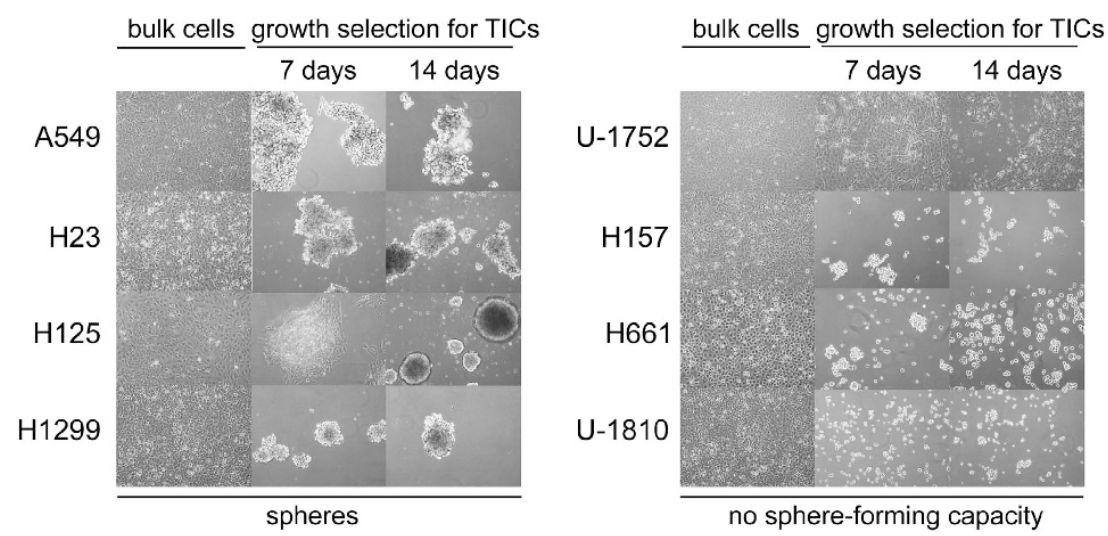

Figure 1 Isolation of TICs from NSCLC cell lines. Formation of spheres in the NSCLC cell lines A549, H23, H125 and H1299 after culture in non-adherent conditions in stem cell media for 7 or 14 days. The morphology of bulk cells grown in standard media is shown in the left panel
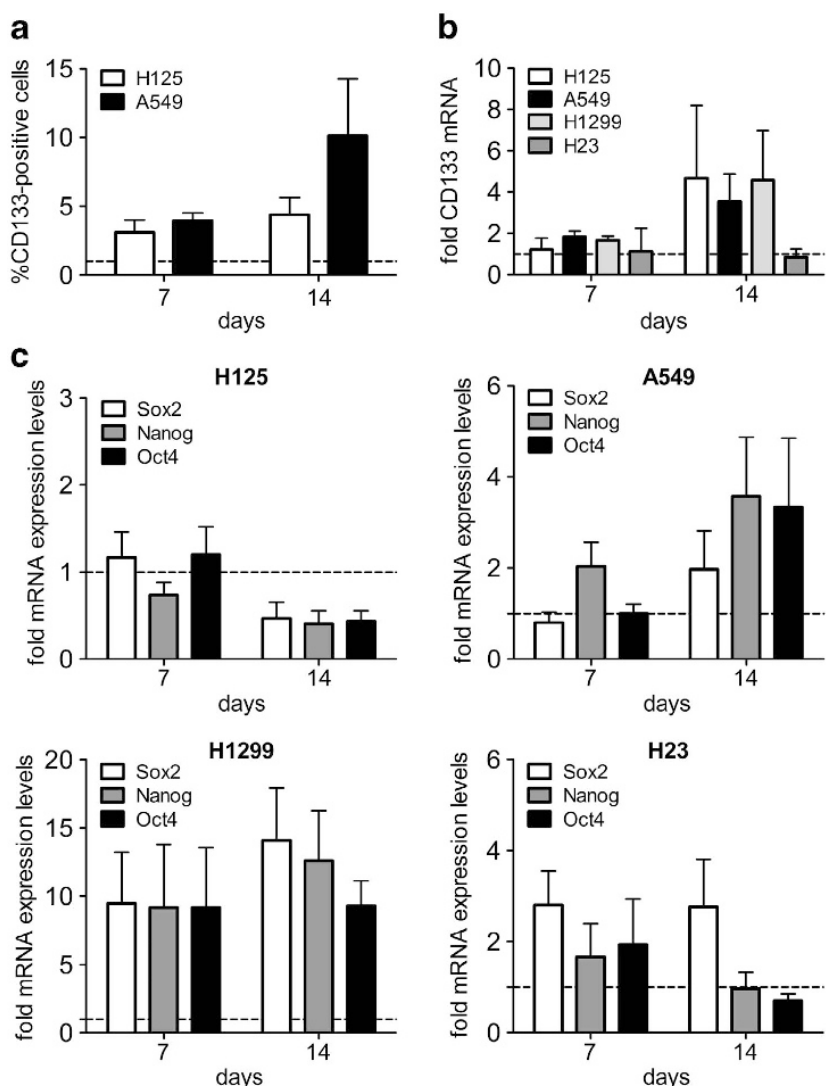

Figure 2 Expression of stem cell-associated markers in NSCLC bulk cells and TICs. (a) A higher percentage of CD133 + cells were found in $\mathrm{H} 125$ and A549 cells after 7 and 14 days of growth in stem cell media as measured by flow cytometry. The threshold was arbitrarily set to $1 \%$ for bulk cells. (b) Increased mRNA expression of CD133 in H125, A549 and H1299 but not in H23 TICs after 14 days of culture in stem cell media. (c) Sox2, Nanog and Oct4 mRNA were increased in A549 and $\mathrm{H} 1299$ but not in $\mathrm{H} 125$ and $\mathrm{H} 23 \mathrm{TICs}$ after 14 days of culture in stem cell media. For (b) and (c), the data are presented as fold change relative to bulk cells, using real-time PCR. mRNA levels were normalized to TBP

NSCLC TICs show impaired cell cycle arrest after DNAdamaging treatment. Reduced checkpoint response was observed in TICs after DNA-damaging treatment (Figures 4b and c). IR (8 Gy) arrested both $\mathrm{H} 125$ and A549 bulk cells in the G2/M phase at $24 \mathrm{~h}$. By contrast, almost no $(\mathrm{H} 125)$ or a less prominent $\mathrm{G} 2$ block (A549) was elicited in TICs (Figure 4b). Cisplatin treatment arrested bulk cells in the $S$ phase after $24 \mathrm{~h}$, which is typical of DNA replication-blocking agents, whereas both $\mathrm{H} 125$ and A549 TICs had a significantly $(P<0.05$ versus bulk) reduced proportion of cells in the $\mathrm{S}$ phase after exposure to $1 \mu \mathrm{M}$ cisplatin, and $10 \mu \mathrm{M}$ cisplatin for $\mathrm{A} 549$ (Figure $4 \mathrm{c}$ ). As expected, ${ }^{17}$ this initial S-phase arrest was relatively transient and followed by a more persistent G2/M arrest. After $48 \mathrm{~h}, \mathrm{H} 125$ bulk cells treated with $1 \mu \mathrm{M}$ cisplatin had progressed into $\mathrm{G} 2 / \mathrm{M}$, but were still blocked in the $\mathrm{S}$ phase after $10 \mu \mathrm{M}$ cisplatin (data not shown). In H125 TICs, we observed a trend towards less G2/M accumulation $(P=0.09)$. In $A 549$ bulk cells, which were less cisplatin-sensitive than $\mathrm{H} 125$ cells, the G2/M arrest after $48 \mathrm{~h}$ was most evident after $10 \mu \mathrm{M}$ cisplatin. Again, significantly less G2/M accumulation of TICs was observed $(P<0.05)$. Altogether, NSCLC TICs displayed shortened G2 checkpoint response after IR as well as reduced $S$ and G2/M checkpoint response after cisplatin treatment, which might contribute to their refractory phenotype.

NSCLC TICs show diminished apoptotic response after DNA-damaging treatment. DNA damage-induced apoptosis following IR and cisplatin treatment was evaluated by comparing PARP cleavage and caspase 3 activation in TICs and bulk cells (Figure 5). Consistent with their increased resistance, $\mathrm{H} 125 \mathrm{TICs}$ showed less PARP cleavage at $24 \mathrm{~h}$ after either IR (Figure 5a) or cisplatin treatment (Figure 5b). Moreover, reduced caspase 3 activation was observed in $\mathrm{H} 125(P=0.06)$ and A549 $(P<0.05)$ TICs after cisplatin treatment (Figure $5 \mathrm{c}$ ). Thus, active caspase 3 was detected in about $30 \%$ of both $\mathrm{H} 125$ and $\mathrm{A} 549$ bulk cells after $48 \mathrm{~h}$ treatment with $10 \mu \mathrm{M}$ cisplatin, whereas in comparison, only 15 and $10 \%$ of H125 and A549 TICs showed caspase-3 activation, respectively.

NSCLC TICs exhibit diminished activation of DDR after DNA-damaging treatment. We hypothesized that differences in the cellular capacity to repair DNA damage could contribute to the increased resistance of NSCLC TICs. For 
a

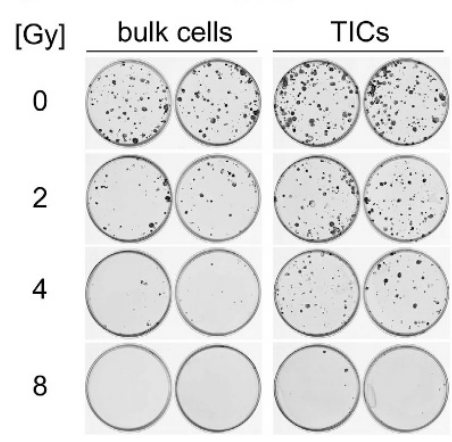

b

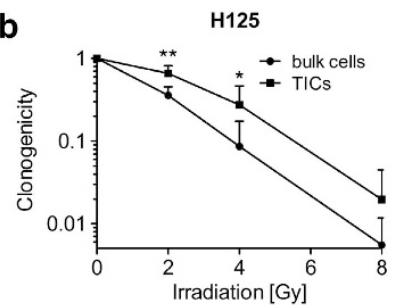

C

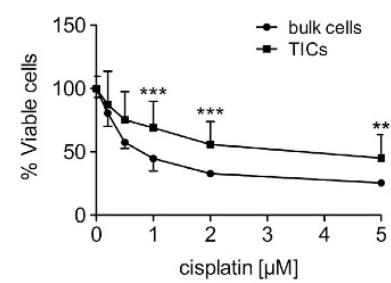

A549

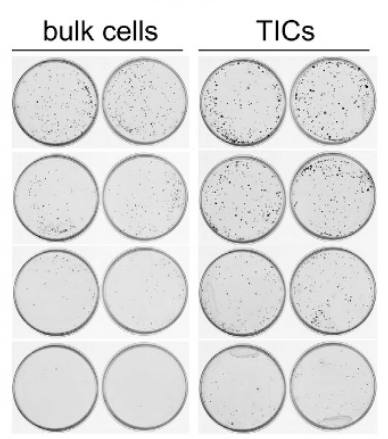

A549

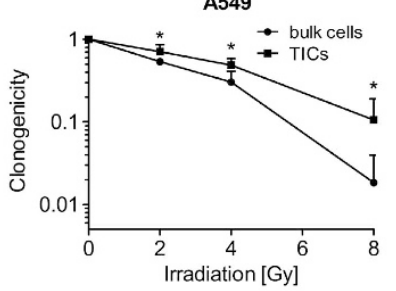

A549

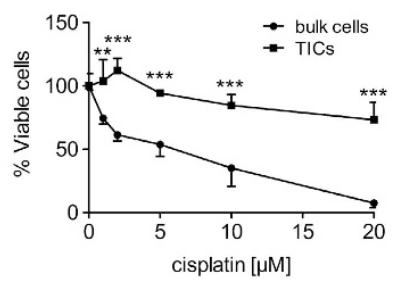

Figure 3 Increased RT and CT resistance in NSCLC TICs. The clonogenic capacity of H125 and A549 TICs and bulk cells irradiated with 2, 4 or 8 Gy was assessed. (a) Scanned plates from a representative experiment. (b) The colony number relative to untreated cells (average \pm S.D. of three independent experiments). (c) Cell viability of $\mathrm{H} 125$ and A549 bulk cells and TICs after $72 \mathrm{~h}$ of continuous cisplatin exposure was measured using MTT assay. ${ }^{*} P<0.05$; ${ }^{* *} P<0.01 ;{ }^{* *} P<0.001$

these mechanistic studies, we included the IR-mimetic drug bleomycin in addition to IR and cisplatin. As shown in Figures $6 \mathrm{a}$ and $\mathrm{b}$ (for quantification data, see Supplementary Figure S2), there were no major differences in total level of the key DDR regulators ATM and the non-homologous end-joining protein DNA-PKcs comparing $\mathrm{H} 125$ bulk cells and TICs, regardless of the presence of DNA damage. Next, we analyzed their activation pattern and in $\mathrm{H} 125$ bulk cells, pDNA-PK (pS2056), pATM (pS1981), as well as the DNA double-strand break marker $\gamma \mathrm{H} 2 \mathrm{AX}(\mathrm{H} 2 \mathrm{~A}$ histone family, member X; pS139) were all increased after IR (Figure 6a) and after bleomycin treatment (Figure 6b). A higher basal level of $\gamma \mathrm{H} 2 \mathrm{AX}$ was noted in TICs compared with bulk cells, therefore the fold induction $1 \mathrm{~h}$ after DNA damage (IR, 1.8versus 2.7-fold; bleomycin, 3.9- versus 5.2-fold) was lower in TICS than in bulk cells. In line with this, untreated H125 TICs had longer comet tails than bulk cells, suggesting increased levels of spontaneous DNA damage (Supplementary Figure 3). Notably, DNA damage-induced phosphorylation of DNA-PK, ATM and the ATM substrate KAP1 (pS824) after $I R$, bleomycin and cisplatin was reduced in $\mathrm{H} 125$ TICs compared with bulk (Figures 6a and b). Similar patterns of

reduced PATM and pKAP1 response after IR were also seen in A549, H1299 and H23 TICs.

Because of the observed differences in the ATM pathway, we addressed if the activation pattern of the ATM substrate checkpoint kinase 2 (Chk2) was altered in H125 TICs. Irradiated TICs mounted a more robust initial Chk2 (pT68), whereas Chk2 activation in bulk cells was less prominent. Coherent with the ATM and KAP1 data, bleomycin activated Chk2 and structural maintenance of chromosomes 1 (SMC1), another ATM substrate, to a lower extent in H125 TICs. By contrast, the Chk2 target cell division cycle 25 homolog A (Cdc25A) did not show marked differential regulation in TICs versus bulk cells (Figure $6 \mathrm{c}$ ). Both bleomycin and cisplatin treatment induced the monoubiquitination of FANCD2, a DNA damage-responsive protein, in bulk cells, whereas the induction was less pronounced in $\mathrm{H} 125 \mathrm{TICs}$ and absent in A549 TICs (Figures 6b and c). Rad51, a central player in homologous recombination, ${ }^{18}$ was unchanged by bleomycin treatment. Taken together, our data suggest that NSCLC TICs have increased levels of spontaneous $\gamma \mathrm{H} 2 \mathrm{AX}$-decorated DNA lesions and yet were unable to mount an efficient DDR after treatment with exogenous DNA-damaging agents.

To determine if reduced DDR activation is related to therapy resistance, we evaluated cisplatin-induced apoptotic response in $\mathrm{H} 125$ bulk cells in the presence or absence of DNA-PKcs (NU7026) or ATM (KU55933) inhibitors (Figure 6d). Incubation with the ATM inhibitor before and during cisplatin treatment reduced PARP cleavage and the DNA-PK inhibitor in combination with cisplatin caused a minor reduction in PARP cleavage compared with cisplatin alone, suggesting that ATM and its substrates are of major importance for the resistant phenotype of TICs.

Xenografts derived from NSCLC TICS show impaired cisplatin response. To verify that NSCLC TICs are refractory to cisplatin also in vivo, we injected severecombined immunodeficiency (SCID) mice with $\mathrm{H} 125$ bulk cells and TICs, respectively, and assessed tumor growth (median tumor size) over time. As shown in Figure 7, xenografts derived from $\mathrm{H} 125$ bulk cells (bulk tumors) grew slower during cisplatin treatment $(P=0.067$ versus mock treatment), but regained full proliferative capacity when cisplatin treatment was ended (indicated by an arrow), and eventually reached similar sizes as the mock-treated bulk tumors. On the contrary, xenografts derived from TICs were highly resistant to cisplatin treatment and grew equally well regardless of whether the mice were treated with cisplatin (Figure 7). Thus, the in vivo data further support a DNA damage treatment-refractory phenotype of NSCLC TICs.

\section{Discussion}

TICs display resistance to CT and RT in several tumor types. ${ }^{19}$ Although a few studies have suggested the existence of a therapy-resistant phenotype of NSCLC TICs, most of the underlying molecular events remain elusive. ${ }^{20}$ Here we demonstrate that NSCLC TICs are refractory to both RT and the DNA-damaging CT agent cisplatin in vitro, and cisplatin in vivo. Importantly, we show that NSCLC TICs exhibited inadequate activation of DDR signaling, impaired checkpoint 
b

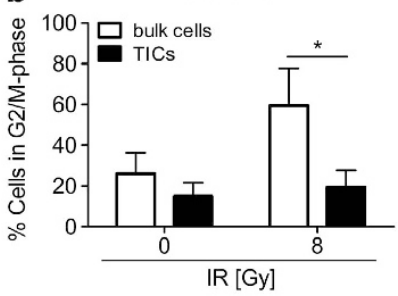

H125 $24 \mathrm{~h}$

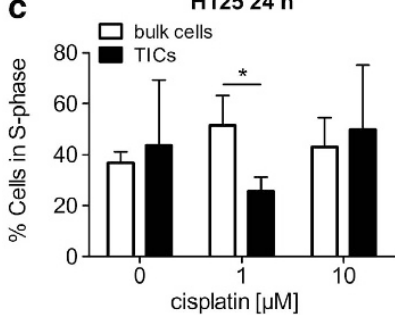

H125 $48 \mathrm{~h}$
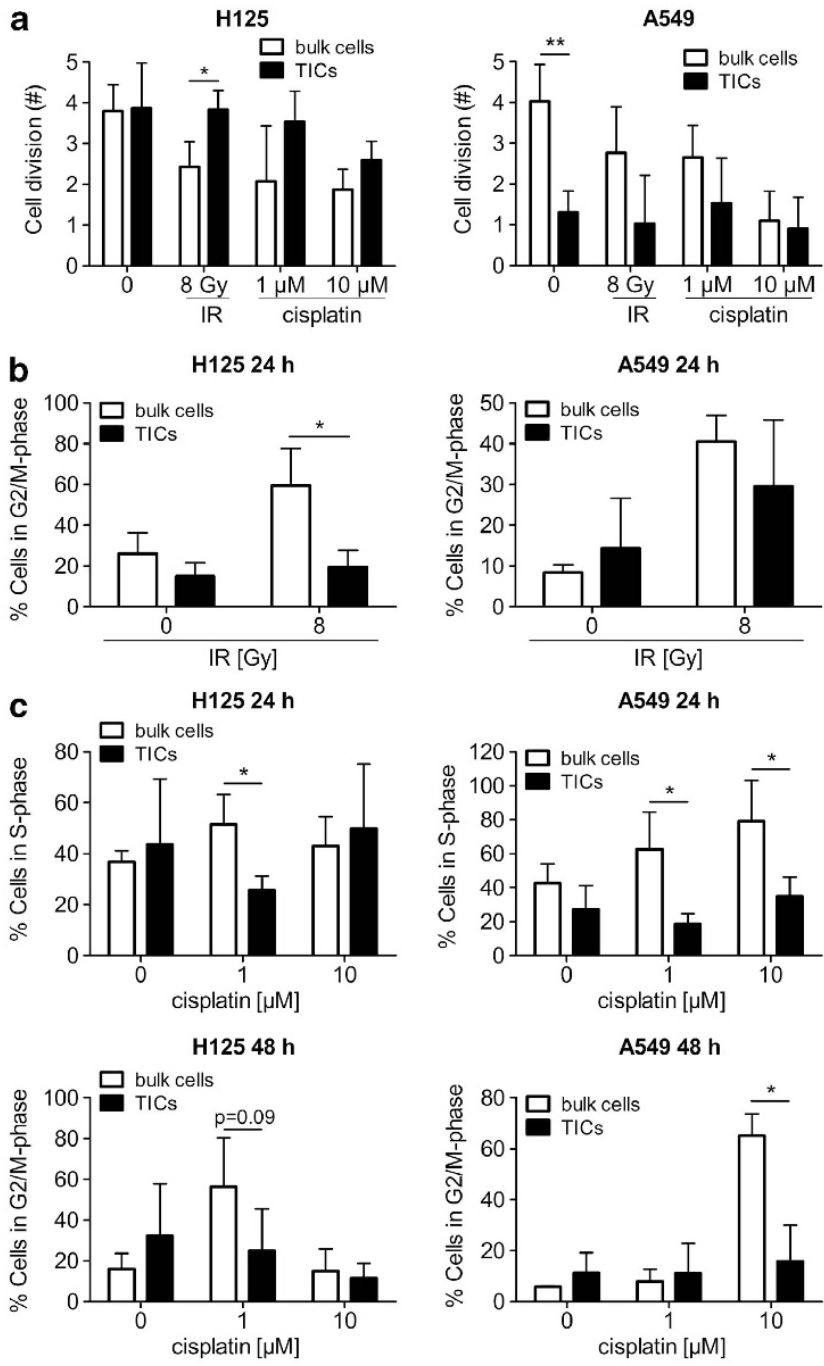

A549 $24 \mathrm{~h}$

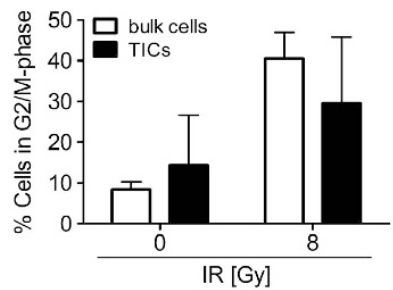

A549 $24 \mathrm{~h}$

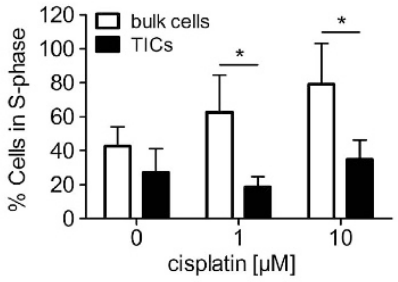

A549 $48 \mathrm{~h}$

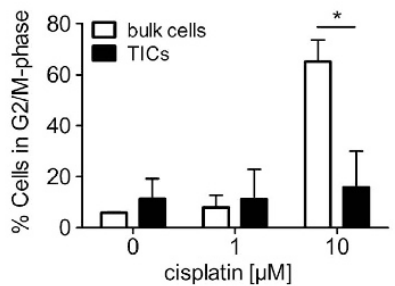

Figure 4 Impaired G2/M or S-phase arrest in NSCLC TICs after IR and cisplatin treatment. (a) Proliferation of IR and cisplatin-treated $\mathrm{H} 125$ and A549 bulk cells and TICs measured by CFSE labeling. The number of cell divisions since drug treatment (i.e. $72 \mathrm{~h}$ ) is presented for bulk cells and TICs. (b-c) Cell cycle distribution of $\mathrm{H} 125$ and A549 bulk cells and TICs after 8 Gy IR and 1 or $10 \mu \mathrm{M}$ cisplatin treatment. (b) Proportion of cells in the G2/M phase $24 \mathrm{~h}$ post IR. (c) Upper panel: Proportion of cells in the $S$ phase after $24 \mathrm{~h}$ of continuous cisplatin treatment. Lower panel: Proportion of cells in the G2/M phase after $48 \mathrm{~h}$ of continuous cisplatin treatment. ${ }^{*} P<0.05 ;{ }^{* *} P<0.01$

arrest and a significantly attenuated apoptotic response. Collectively, our data suggest that reduced DDR activity may contribute to therapy resistance in NSCLC by allowing these cells to evade cell death in the face of extensive treatmentinflicted DNA damage.

One of the main characteristics of TICs is their sphereforming capacity, which was observed in four out of eight cell lines. Notably, cells of adenocarcinoma or adenosquamous histology formed distinct spheres, whereas the majority of large-cell and squamous carcinoma cells did not. However, others have reported the presence of side populations also from squamous and large-cell carcinoma cell lines, ${ }^{6,21}$ indicating that all NSCLC histological subtypes may contain rare fractions of cells with TIC characteristics.
To confirm a TIC phenotype of the NSCLC spheres formed, we analyzed several stem cell markers and revealed that three out of four sphere-forming cell lines (A549, H125 and $\mathrm{H1299}$ ) had increased the proportion of cells expressing CD133. However, H23 spheres did not, indicating that CD133 may not be a uniform marker for NSCLC TICs, as reported earlier. $^{22}$ Aside from CD133, ${ }^{10}$ NSCLC TICs have been reported to show increased expression of several stem cell markers, including Sox2, Oct4, Nanog, 9,23,24 aldehyde dehydrogenase $1^{21}$ and CD44. ${ }^{25}$ The increased expression of Sox2, Nanog and Oct4 in A549 TICs was consistent with one ${ }^{7}$ but not another report, ${ }^{5}$ indicating some variance in the TIC phenotype. We did not detect increased expression of Sox2/ Nanog/Oct4 in H125 TICs or Nanog/Oct4 in H23 TICs despite their clear sphere-forming capacity. Importantly, this heterogeneity in the expression of putative stem cell markers in NSCLC TICs did not affect their response pattern following DNA-damaging treatment.

A novel finding in this study is that NSCLC TICs enriched as spheres display apparent radiation resistance compared with bulk cells. This supports studies of TICs in other tumor types such as glioma ${ }^{11}$ where isolated primary $\mathrm{CD} 133+$ cells were more radioresistant than CD133 - cells. We could also confirm the previously reported cisplatin-refractory phenotype of NSCLC TICs. ${ }^{5,8,9}$ Although an increased expression of ATP7B in TICs could partly contribute to platinum resistance, the increase was relatively minor and is unlikely to account for the large differences in cytotoxicity that we observed. Using a combination of quantitative real-time PCR, immunofluorescence, flow cytometry and comet assay, we conclusively show that cisplatin can be transported into TICs where it forms adducts and induce DNA strand breaks at comparable levels as in bulk cells. Likewise, both bleomycin and IR caused similar amounts of DNA damage in both bulk cells and TICs, as shown by the comet assay (Supplementary Figure 3).

TICs have been shown to possess several features associated with resistance to DNA damage, including slower cell cycle kinetics, increased DNA repair capacity and resistance to apoptosis. ${ }^{26}$ Here, we present novel data demonstrating reduced cell cycle arrest after IR or cisplatin treatment of NSCLC TICs. This is mechanistically important as alterations in the checkpoint response might allow TICs to evade the proapoptotic effects of RT/CT and thereby contribute to resistance. CFSE confirmed that the growth of TICs was essentially unchanged following DNA-damaging treatment. As untreated $\mathrm{H} 125$ TICs and bulk proliferated at comparable rates, the activation of cell cycle checkpoints in TICs was unlikely to simply be delayed and their increased therapy resistance was not purely due to quiescence. Although slower growth of untreated A549 TICs may partly account for their resistance, both $\mathrm{H} 125$ and A549 TICs showed impaired apoptotic response following DNA-damaging treatment, which indicates that the rate of proliferation was not crucial for the differences in chemo- and/or radiosensitivity. To our knowledge, only one other study has reported decreased cell cycle arrest in CD133 + cells, albeit observed in liver cancer cells at a much higher dose of radiation (15-20 Gy). ${ }^{27}$ In concordance with our findings, CD133 + liver cancer cells also showed diminished PARP cleavage and Annexin V-staining after IR. ${ }^{27}$ Taken together, 
a

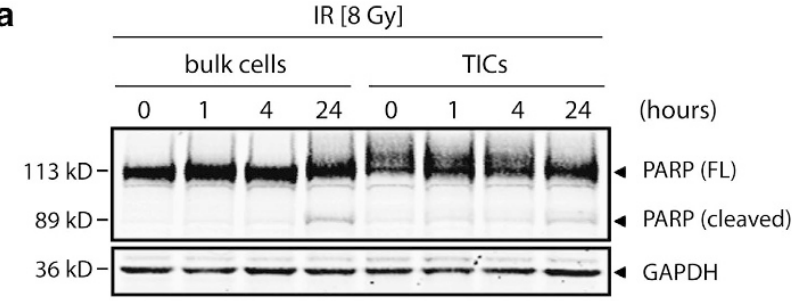

b
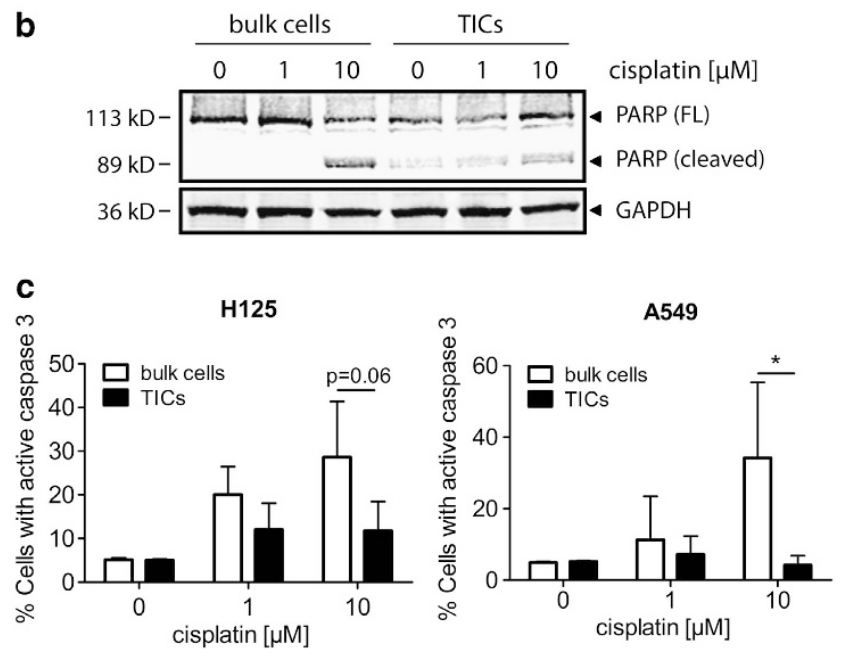

Figure 5 NSCLC TICS display reduced PARP cleavage and caspase 3 activation after IR and cisplatin treatment. (a and $\mathbf{b}$ ) PARP cleavage was used as a marker of apoptosis in H125 TICs versus bulk cells. (a) Western blot analysis of PARP full-length and cleavage fragment, 1, 4 and $24 \mathrm{~h}$ after $8 \mathrm{~Gy} \mathrm{IR}$. (b) Western blot analysis of PARP full-length and cleavage fragment $24 \mathrm{~h}$ after 1 and $10 \mu \mathrm{M}$ of continuous cisplatin treatment. A representative blot of two independent experiments is shown. Glyceraldehyde 3-phosphate dehydrogenase (GAPDH) was used as a loading control. (c) Reduced activation of caspase 3 after $48 \mathrm{~h}$ of 1 and $10 \mu \mathrm{M}$ continuous cisplatin in $\mathrm{H} 125$ and A549 TICs, as measured by flow cytometry. The threshold was arbitrarily adjusted to $5 \%$ for untreated cells. ${ }^{*} P<0.05$

these data suggest that transient checkpoint responses may represent a hitherto unappreciated mechanism that allows TICs to evade DNA damage-induced apoptosis.

To obtain further mechanistic insight, we profiled several DNA repair proteins, and interestingly, NSCLC TICs tend to show increased basal levels of the DNA damage marker $\gamma \mathrm{H} 2 \mathrm{AX}$. Taken together with data from the comet assay, we hypothesize that TICs may harbor more spontaneous DNA damages and that the increased baseline $\gamma \mathrm{H} 2 \mathrm{AX}$ could reflect a subpopulation primed to respond to DNA damage, as previously reported for $\mathrm{CD} 133+$ glioma cells. ${ }^{11}$ Notably, NSCLC TICs showed diminished phosphorylation of H2AX, ATM, DNA-PKcs and FANCD2 monoubiquitination after exposure to DNA-damaging agents. Given that a similar reduced activation of $\gamma \mathrm{H} 2 \mathrm{AX}$ after DNA damage has been reported in mammary $\mathrm{TICs},{ }^{28}$ it raises the question as to whether or not the TICs are a pre-existing population with intrinsically altered DDR or if these properties could be affected by culture and selection. This has been difficult to address in our system, as we have not sorted out the CD133 + cells before the sphere culturing process. Nonetheless, differential expression of DDR proteins was reported in sorted CD133 + versus CD133 - cells shortly after isolation from the primary tumor, ${ }^{11}$ implying that TIC properties differ inherently from their bulk counterpart, and is not solely a result of in vitro culture. In addition, cisplatin normally binds to serum proteins, ${ }^{29}$ so having no serum in the stem cell media should increase its potency and TICs should incur more DNA damage; however, equal damage was revealed by the comet assay. Interestingly, while the bulk cells have repaired most of their damage $3 \mathrm{~h}$ after bleomycin treatment, as judged by the disappearance of comet tails, DNA strand breaks appeared to persist in TICs, suggesting that the DNA repair capacity of TICs may be diminished.

A hyper-active DDR is usually considered to enhance TICs survival, ${ }^{11}$ but there is also data from studies on glioma where no differences in DNA base excision, single-strand break repair or resolution of $\gamma \mathrm{H} 2 \mathrm{AX}$ nuclear foci were found between bulk cells and TICs. ${ }^{30}$ Our data clearly demonstrate reduced activation of an ATM and KAP1-mediated pathway in NSCLC TICs. Importantly, bulk H125 cells cotreated with the ATM inhibitor KU55933 decreased cisplatin-induced PARP cleavage, uncovering a causal relationship between reduced ATM signaling and resistance to DNA-damaging treatment. ATM is a key driver of the DNA damage signaling network and is required for cell cycle arrest and DSB repair through homologous recombination. ${ }^{31,32}$ Therefore, the reduced ATM signaling is in accordance with the impaired cell cycle arrest that we see. Notably, mutations of the ATM gene in B-cell chronic lymphocytic leukemia patients were associated with impaired CT response and reduced overall and treatment-free survival. ${ }^{33}$ ATM, ATR and DNA-PK rapidly phosphorylates the transcriptional repressor KAP1 on Ser824 upon DNA damage ${ }^{31}$ leading to increased expression of KAP1 target genes involved in checkpoint control (p21 ${ }^{\mathrm{WAF} 1 / \mathrm{Cip} 1}$ ) and apoptosis (Bcl-2-associated $\mathrm{X}$ protein (Bax), p53 upregulated modulator of apoptosis (Puma), Noxa). ${ }^{34}$ Therefore, the impaired phosphorylation of KAP1 might provide a mechanistic explanation for the reduced DNA damage-induced cell cycle arrest and apoptosis in NSCLC TICs.

Persistent checkpoint arrest is detrimental to many tumor cells. Consequently, the transient arrest followed by checkpoint recovery, especially coupled to decreased apoptosis, will favor survival of TICs. The general conclusion of our study is that TICs are able to survive both a higher basal level of DNA damage and to escape the checkpoint arrest despite the presence of DNA damage. This correlates well with data showing higher mutation rates in a subtype of glioblastoma defined on the basis of a CD133-related gene expression signature. ${ }^{35}$ Further studies are needed to investigate the DNA repair activity in TICs and to validate the findings using siRNA towards primarily ATM and KAP1. An increased knowledge of the specific alterations of these components in TICs may open up for therapeutic interventions as a way to improve the RT and/or CT response of NSCLC.

\section{Materials and Methods}

Cell culture. The human NSCLC cell lines A549 and H23 (adenocarcinomas), H125 (adenosquamous), H157, H661 and H1299 (large cell carcinoma) are commercially available from ATCC (American Type Culture Collection; Manassas, VA, USA), whereas U-1752 (squamous cell carcinoma) and U-1810 (mixed large cell/adenocarcinoma) were established at Uppsala University as described 


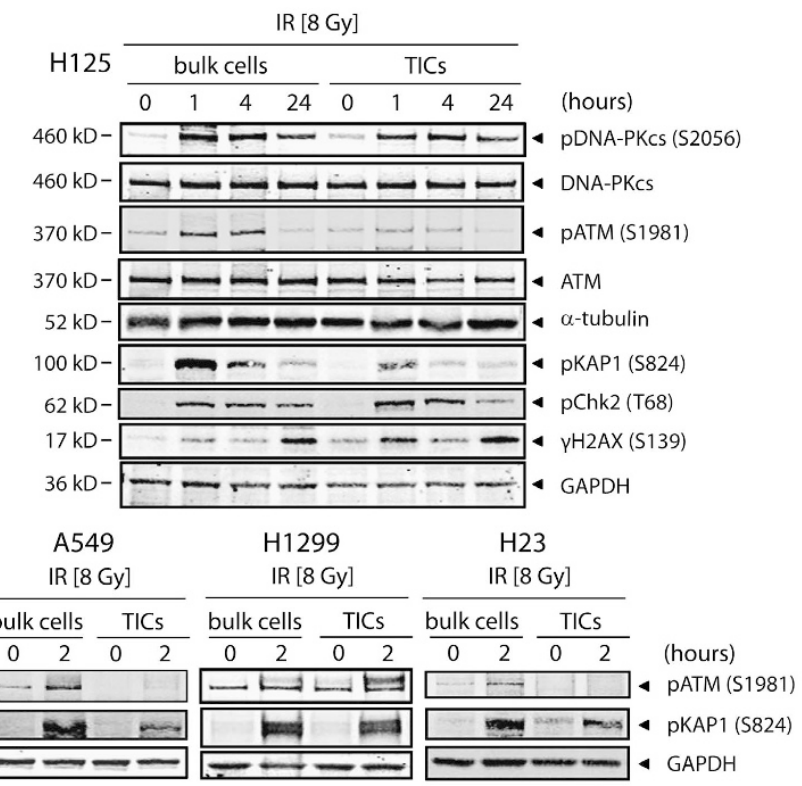

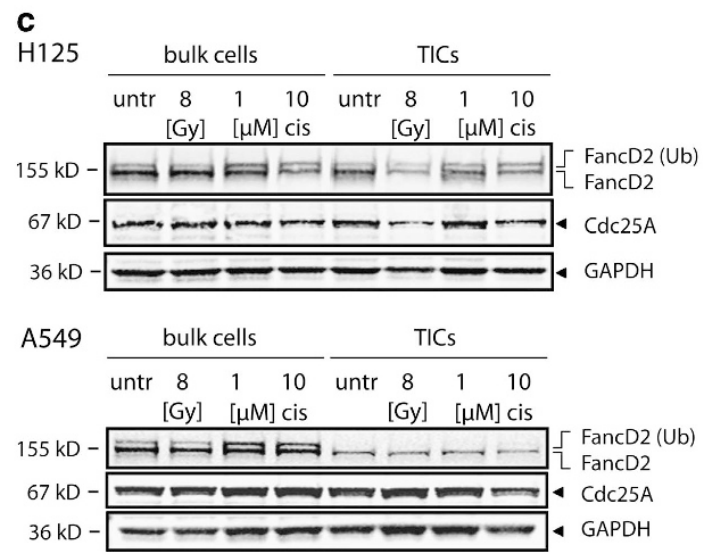

d

$$
\begin{aligned}
& \text { H125 bulk cells TICs bleomycin } \\
& \begin{array}{lllllll}
0 & 2.5 & 0 & 2.5 & {[\mu \mathrm{g} / \mathrm{ml}]}
\end{array}
\end{aligned}
$$

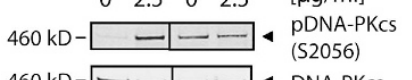

$$
\begin{aligned}
& \begin{array}{l}
460 \mathrm{kD}-\square-\square- \\
370 \mathrm{kD}-\square- \\
\hline
\end{array} \\
& 370 \mathrm{kD}-\boldsymbol{\square}=\cdots 4 \text { ATM }
\end{aligned}
$$

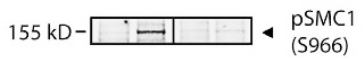

$$
\begin{aligned}
& 100 \mathrm{kD}-\square-\square+\square \text { (S824) } \\
& 62 \mathrm{kD}-\cdots-\square+\begin{array}{l}
\mathrm{pChk2} \\
\text { (T68) }
\end{array} \\
& 52 \mathrm{kD}-\longrightarrow-\ldots \text {-tubulin } \\
& 155 \mathrm{kD}--=\left\{\begin{array}{l}
\text { FancD2 (Ub) } \\
\text { FancD2 }
\end{array}\right. \\
& 37 \mathrm{kD}----\longrightarrow \operatorname{Rad} 51
\end{aligned}
$$

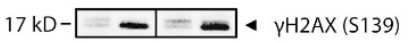

$$
\begin{aligned}
& 52 \mathrm{kD}-\longrightarrow-\longrightarrow \text {-tubulin }
\end{aligned}
$$$$
\text { b }
$$

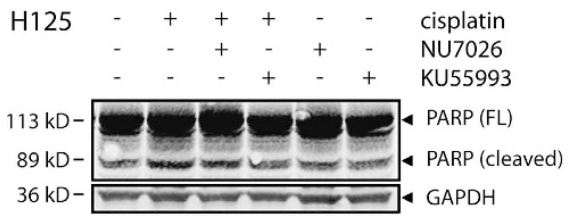

Figure 6 DDR/DNA repair proteins show suboptimal activation in TICS compared with bulk cells. (a) Western blot analysis of $\mathrm{H} 125 \mathrm{bulk}$ cells and TICs, 1,4 and $24 \mathrm{~h}$ after IR, and A549, H1299 and H23 $2 \mathrm{~h}$ after IR with $8 \mathrm{~Gy}$. Phosphorylated and total forms of DNA-PK, ATM and phosphorylated forms of the ATM substrates H2AX, KAP1 and Chk2 were analyzed. $\alpha$-Tubulin or glyceraldehyde 3-phosphate dehydrogenase (GAPDH) was used as loading controls. (b) Western blot analysis of H125 bulk cells and TICs, $4 \mathrm{~h}$ after bleomycin $(2.5 \mu \mathrm{g} / \mathrm{ml})$ or $24 \mathrm{~h}$ after cisplatin $(1$ or $10 \mu \mathrm{M})$ exposure. Phosphorylated and total forms of DNA-PK, ATM, phosphorylated forms of the ATM substrates $\mathrm{H} 2 \mathrm{AX}, \mathrm{KAP} 1, \mathrm{SMC1}$, Chk2 as well as the levels of FANCD2 and Rad51 were analyzed. A representative blot of at least two independent experiments is shown. $\beta$-Tubulin or GAPDH was used as loading controls. (c) Western blot analysis of $\mathrm{H} 125$ and A549 bulk cells and TICs, $24 \mathrm{~h}$ after 8 Gy IR, or 1 or $10 \mu \mathrm{M}$ continuous cisplatin exposure. FANCD2 and cdc25A was assayed. A representative blot of two independent experiments is shown. GAPDH was used as loading control. (d) Western blot analysis of PARP full-length and cleavage fragment $24 \mathrm{~h}$ after $10 \mu \mathrm{M}$ of continuous cisplatin treatment, with or without $1 \mathrm{~h}$ pretreatment with DNA-PKcs (NU7026) or ATM (KU55933) inhibitors (both $10 \mu \mathrm{M}$ ). A representative blot of two independent experiments is shown. GAPDH was used as a loading control

previously. ${ }^{36}$ Bulk cells were grown in RPMI-1640 media supplemented with $10 \%$ heat-inactivated fetal bovine serum (HyClone, Täby, Sweden). To assess the sphere-forming ability, bulk cells were seeded at a density of 10000 cells per $\mathrm{ml}$ in Dulbecco's modified Eagle's medium/F12 media (Lonza, Basel, Switzerland) freshly supplemented with $20 \mathrm{ng} / \mathrm{ml}$ epidermal growth factor, $10 \mathrm{ng} / \mathrm{ml}$ basic fibroblast growth factor (PeproTech, London, UK), $2 \mu \mathrm{g} / \mathrm{ml}$ heparin (Sigma-Aldrich, Stockholm, Sweden) and B27 supplement (Invitrogen, Stockholm, Sweden) in non-adherent plates. Fresh supplements were added at day 3 or 4 and both adherent and non-adherent cells were kept when replating the cells at day 7 . Experiments were started after 10-14 days of culture in stem cell media. Before experiments spheres were trypsinized and mechanically dissociated to generate single cells. For kinase inhibitor experiments, cells were pretreated with $10 \mu \mathrm{M}$ NU7026 (DNA-PKcs inhibitor) or KU55933 (ATM inhibitor) $1 \mathrm{~h}$ before DNA- damaging treatment, and the inhibitors were kept during the $24 \mathrm{~h}$ before cells were pelleted for western blot analysis.

IR procedure. TICs and bulk cells were irradiated with 2,4 or $8 \mathrm{~Gy}$. The IR source was $\mathrm{Co}^{60}$ with a dose rate of $0.4 \mathrm{~Gy} / \mathrm{min}$. At 1, 2, 4, 24 or $48 \mathrm{~h}$ after IR, the cells were pelleted and frozen for western blot analysis or fixed for caspase 3 and cell cycle analysis.

Clonogenic survival assay. Following IR, 500 cells were seeded in RPMI media in $10 \mathrm{~cm}^{2}$ dishes. After 9 days (A549) or 14 days (H125) depending on the cellular growth rate, the resulting colonies were stained using $0.5 \%$ crystal violet in $25 \%$ methanol and colonies containing more than 50 cells were counted. For each radiation dose duplicate samples were prepared. Evaluation of RT response was 

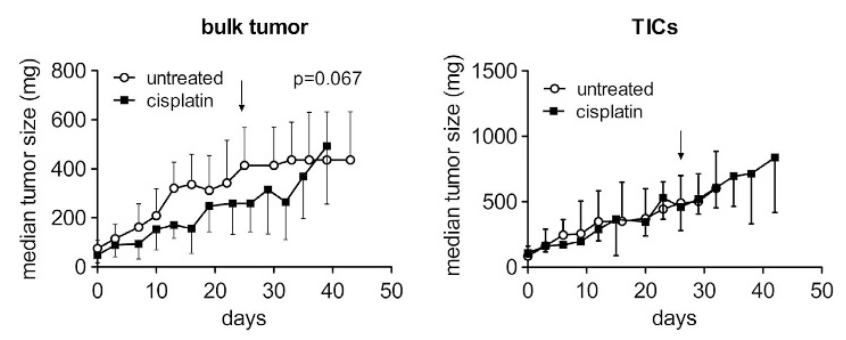

Figure 7 H125 TICs display a cisplatin-resistant phenotype also as mouse xenografts in vivo. Xenografts established from $\mathrm{H} 125$ bulk cells responded to $1 \mathrm{mg} /$ $\mathrm{kg}$ cisplatin treatment by a reduced growth rate, whereas TICs are highly resistant to treatment. Median tumor size \pm S.D. was analyzed over time (bulk, $n=12$; TICs, $n=4$ ). Cisplatin treatment was initiated when tumors reached a size of $100 \mathrm{mg}$ (day 0 ) and were given two times a week. The arrow indicates the last cisplatin treatment. Statistics were calculated using a two-tailed $t$-test comparing all time points

performed using clonogenic survival assay to capture all cell death events, which are delayed with respect to time, including mitotic catastrophe. ${ }^{14}$

MTT cell viability assay. Bulk cells or TICs (4000/well) were seeded in triplicate in 96-well plates and treated with indicated doses of cisplatin (Apoteket, Stockholm, Sweden). After $72 \mathrm{~h}$ of continuous drug exposure, cell viability was assessed using MTT (3-(4,5-dimethylthiazol-2-yl)-2,5-diphenyl-tetrazolium bromide) assay as described previously. ${ }^{37}$ Cell viability of cisplatin-treated cells was compared with untreated cells whose viability was arbitrary set to $100 \%$. For cisplatin response, which primarily induces apoptosis within a 72 -h time frame, ${ }^{17}$ cytotoxicity assays such as MTT are generally used.

Flow cytometry analysis and immunofluorescence. To assess surface CD133 expression, fresh non-fixed cells were resuspended in phosphatebuffered saline (PBS) containing $0.5 \%$ bovine serum albumin and $2 \mathrm{mM}$ EDTA (ethylenediaminetetraacetic acid; Amresco, Solon, OH, USA) and incubated with a phycoerythrin-conjugated CD133 antibody (Miltenyi Biotec, Bergisch Gladbach, Germany) for $20 \mathrm{~min}$ at $4{ }^{\circ} \mathrm{C}$. The threshold level was set to $1 \%$ for bulk cells. For cell tracking experiments, single-cell suspensions of bulk cells and TICs were labeled with CFSE $(2.5 \mu \mathrm{M})$ as previously described and thereafter treated with IR or cisplatin. Cell-associated CFSE fluorescence signals after $72 \mathrm{~h}$ were normalized to controls taken immediately before drug treatment $(t=0 \mathrm{~h})$.

To assess caspase 3 activity and cell cycle distribution, bulk cells or TICs were irradiated with $8 \mathrm{~Gy}$ or treated with 1 or $10 \mu \mathrm{M}$ cisplatin. After 24 or $48 \mathrm{~h}$, cells were fixed in $70 \%$ ethanol. For caspase 3 analysis, cells were washed with PBS and incubated with an FITC-conjugated antibody recognizing the active site of caspase 3 (BD Pharmingen, Stockholm, Sweden) diluted in PBS containing $100 \mu \mathrm{g} / \mathrm{ml}$ digitonin. For cell cycle analysis, the cellular DNA content was analyzed by PI staining as described previously. ${ }^{38}$ For staining of cisplatin adducts, bulk cells or TICs treated with $40 \mu \mathrm{M}$ cisplatin for $6 \mathrm{~h}$ or $10 \mu \mathrm{M}$ cisplatin for $24 \mathrm{~h}$ were fixed in $70 \%$ ethanol and then washed with PBS. Cells were stained using an anti-cisplatinmodified DNA antibody (ab103261; Abcam, Cambridge, UK) diluted in PBS containing $100 \mu \mathrm{g} / \mathrm{ml}$ digitonin over night, followed by a goat anti-rat IgG H\&L (DyLight 488) secondary antibody (ab96887; Abcam) for $2 \mathrm{~h}$. To keep the TICs separated, cells were taken up in cell dissociation solution (Sigma-Aldrich). PBS was added $(1: 1)$ before cells were recorded using FACS Calibur and analyzed using the CellQuest Software (BD Bioscience, Franklin Lakes, NJ, USA) for CD133 expression, CFSE retention, caspase 3 activity and cisplatin adduct formation, or ModFit LT (Verity Software House, Topsham, ME, USA) for the analysis of cell cycle distribution. The cisplatin adduct-stained cells were put out on glass slides and mounted using mounting media containing 4',6-diamidino-2-phenylindole (DAPI, Vectashield, Vector Labs Inc., Burlingame, CA, USA) for nuclear staining. Images were acquired on a ZEISS Axioplan 2 imaging microscope using Zeiss $\times 20$ lens at a fixed exposure time and processed using the Axiovision software (Carl Zeiss Microlmaging, Göttingen, Germany).

Quantitative real-time PCR analysis of stem cell markers. To assess CD133, Sox2, Nanog and Oct4 expression, total RNA was prepared using Trizol reagent (Invitrogen) and cleaned using RNeasy Mini Kit (Qiagen, Sollentuna, Sweden). RNA was reverse transcribed into cDNA using Reverse Transcription
Reagents and random hexamer primers (Applied Biosystems, Carlsbad, CA, USA). Analyses were performed in duplicate on a 7900 Fast Real-Time PCR System with Fast SYBR Green reagents (Applied Biosystems) and Fast program, initiated at $95^{\circ} \mathrm{C}$ for $20 \mathrm{~s}$, followed by 40 cycles of $95^{\circ} \mathrm{C}$ for $1 \mathrm{~s}$ and $60^{\circ} \mathrm{C}$ for $20 \mathrm{~s}$. The specificity of the reactions was analyzed by melting curve analysis to confirm the presence of a single amplified product. mRNA levels were normalized to TATA binding protein (TBP) to confirm equal CDNA input, using the $2^{-\Delta \Delta C t}$ method for calculation of the relative expression values. The mRNA levels are expressed as fold to bulk cells in Figure 2. Primer sequences were: CD133 - forward, $5^{\prime}$-TACAA CGCCAAACCACGACTG T-3', reverse, 5'-TCTGAACCAATGGAATTCAAGACC CTTT-3'; Sox2 - forward, 5'-CACCCCTGGCATGGCTCTT-3', reverse, 5'-GAGCT G GCCTCGGACTTGA-3'; Nanog - forward, 5'-AACAACTGGCCGAAGAATAGC AATG-3', reverse, 5'-TCCCTGGTGGTAGGAAGAGTAAAGG-3'; Oct4 - forward, 5'-AGCCCTCATTTCACCAGG CC-3', reverse, 5'-TGGGACTCCTCCGGGT TTTG-3'; CTR1 - forward, 5'-GGGTTAAGATTCGGAGAGAGAGGTG-3', reverse, 5'-GTCCATATAGCTCATCCCCATATGGT-3'; ATP7B - forward, 5'-GAATCTG CAGAAAGAAGCTGG TGT T-3', reverse, 5' -CCATCAAGGCAACCAACACGG-3'; and TBP - forward, $5^{\prime}$-CACGAACCACGGCACTGATT-3', reverse, $5^{\prime}$-TTTTCTTG CTGCCAGTCTGGAC-3'.

Western blot analysis. Protein was extracted from cell pellets using RIPA buffer ( $50 \mathrm{mM}$ Tris- $\mathrm{HCl}$ (pH 7.4), $150 \mathrm{mM} \mathrm{NaCl}, 0.5 \%$ Igepal, $5 \mathrm{mM}$ EDTA (pH 8.0), $0.1 \%$ SDS) supplemented with PhosStop and Protease inhibitor cocktail tablets (Roche Diagnostics, Basel, Switzerland). Proteins were separated on 3-8\% Trisacetate gradient gels in NuPage Tris-acetate running buffer (Invitrogen) or 4-12\% Bis-Tris gradient gels in NuPage MOPS running buffer (Invitrogen), depending on the size of the protein to be analyzed and transferred to nitrocellulose membrane (Hybond ECL; Pharmacia Biotech, GE Healthcare, Uppsala, Sweden), which was blocked in $5 \%$ BSA and probed with different primary antibodies. The following primary antibodies were used: $\gamma \mathrm{H} 2 \mathrm{AX}$ and pDNA-PKcs (pSer139; ab2893 and pSer2056; ab18192, respectively; Abcam), total DNA-PKcs (MS-423P0; Thermo Fisher Scientific, Fremont, CA, USA), pATM (pSer1981; 05-740; Upstate/Millipore, Solna, Sweden), total ATM and FANCD2 (1549-1 and 2986-1, respectively; Epitomics, Burlingame, CA, USA), pKAP1 and pSMC1 (pSer824; A300-767A and pSer966; A300-050A, respectively; Bethyl Laboratories, Montgomery, TX, USA). PARP, cdc25A and $\alpha$-tubulin (sc-7150, sc-97 and sc-5286, respectively; Santa Cruz Biotechnology, Santa Cruz, CA, USA), pChk-2 (pThr68, no. 2661; Cell Signaling, Danvers, MA, USA), $\beta$-tubulin (T7816; Sigma-Aldrich) and GAPDH (no. 2275 PC-1; Trevigen, Gaithersburg, MD, USA). The membranes were incubated with primary antibodies overnight at $4{ }^{\circ} \mathrm{C}$, followed by probing with either infrared dye-conjugated goat anti-rabbit or -mouse secondary antibodies (LI-COR, Cambridge, UK) for $45 \mathrm{~min}$ at room temperature. The membrane was scanned and quantified using the Odyssey Sa Infrared Imaging System (LI-COR). A representative blot of three independent experiments is shown, unless otherwise stated in the figure legend.

Comet assay. H125 bulk cells and TICs were treated with $5 \mu \mathrm{g} / \mathrm{ml}$ bleomycin or 8 Gy IR for 1 and $3 \mathrm{~h}$, or $40 \mu \mathrm{M}$ cisplatin for 16 and $24 \mathrm{~h}$. A total of 20000 cells per $\mathrm{ml}$ in PBS were mixed with low melting agarose at a 1:10 ratio and 900 cells were added per slide to allow to solidify. The cells were lysed by incubating the slides in lysis buffer (supplied by the kit; Trevigen) for $2 \mathrm{~h}$. This was followed by a 30-min incubation in neutral comet running buffer before the slides were put in an electrophoresis tray to allow DNA to migrate for $45 \mathrm{~min}$. Slides were immersed in DNA precipitation buffer for $30 \mathrm{~min}$ followed by incubation in $70 \%$ ethanol for another $30 \mathrm{~min}$. The slides were dried at $37^{\circ} \mathrm{C}$ for $15 \mathrm{~min}$ before the addition of $100 \mu \mathrm{l}$ SYBR Gold to each sample for $30 \mathrm{~min}$. Following another drying step, the comets were analyzed at a $\times 20$ magnification using a fluorescence microscope.

Xenograft experiments. All parts of the experiment were performed according to the Swedish Ethical guidelines for animal experiments and were approved by the Animal Ethical committee in Stockholm, Sweden. Female SCID mice in a BALB/c background, at an age of 8-10 weeks at the time of inoculation, were used to establish xenografts. Xenografts were established by subcutaneously injecting one million $\mathrm{H} 125$ bulk or TICs in $100 \mu \mathrm{l}$ PBS in the right-side flank of the mice. The tumor sizes were monitored two times a week and calculated according to the formula: tumor weight $=$ length $\times$ width $^{2} / 2$, as described in Gallo et al..$^{39}$ When a tumor reached $100 \mathrm{mg}$, the mouse was included in the study (day 0) and allocated either to no treatment (injected with 
saline alone) or to intraperitoneal injections of $1 \mathrm{mg} / \mathrm{kg}$ cisplatin in a volume of $100 \mu \mathrm{l}$. The mice were treated two times a week, a maximum of nine times in total. The mice were killed if the tumor size approached $1200 \mathrm{mg}$ or if the health conditions of the mice were severely impaired.

Statistics. All values are expressed as mean \pm S.D. from three independent experiments, unless otherwise stated in the figure legend. Comparison between two groups was made using an unpaired two-tailed $t$-test; $P<0.05$ was considered significant.

\section{Conflict of Interest}

The authors declare no conflict of interest

Acknowledgements. This study was supported by grants from the Swedish Cancer Society (to RL), the Stockholm Cancer Society (to RL and KV), the Swedish Research Council, The Swedish National Board of Health and Welfare, the Stockholm County Council, Karolinska Institutet Research Funds, the Swedish Research Council and the European Union (FP7-KBBE-2010-4 SPECIAL). LL's employment was supported by a dedicated post doctor grant on LC research from the Swedish Cancer Society.

1. Perona R, Lopez-Ayllon BD, de Castro Carpeno J, Belda-Iniesta C. A role for cancer stem cells in drug resistance and metastasis in non-small-cell lung cancer. Clin Transl Oncol 2011; 13: 289-293.

2. Chang A. Chemotherapy, chemoresistance and the changing treatment landscape for NSCLC. Lung Cancer 2011; 71: 3-10.

3. Toschi L, Cappuzzo F. Impact of biomarkers on non-small cell lung cancer treatment Target Oncol 2010; 5: 5-17.

4. Pine SR, Marshall B, Varticovski L. Lung cancer stem cells. Dis Markers 2008; 24: 257-266.

5. Bertolini G, Roz L, Perego P, Tortoreto M, Fontanella E, Gatti L et al. Highly tumorigenic lung cancer $\mathrm{CD} 133+$ cells display stem-like features and are spared by cisplatin treatment. Proc Natl Acad Sci USA 2009; 106: 16281-16286.

6. Ho MM, Ng AV, Lam S, Hung JY. Side population in human lung cancer cell lines and tumors is enriched with stem-like cancer cells. Cancer Res 2007; 67: 4827-4833.

7. Hsu HS, Lin JH, Huang WC, Hsu TW, Su K, Chiou SH et al. Chemoresistance of lung cancer stemlike cells depends on activation of Hsp27. Cancer 2011; 117: 1516-1528.

8. Eramo A, Lotti F, Sette G, Pilozzi E, Biffoni M, Di Virgilio A et al. Identification and expansion of the tumorigenic lung cancer stem cell population. Cell Death Differ 2008; 15 504-514.

9. Chen YC, Hsu HS, Chen YW, Tsai TH, How CK, Wang CY et al. Oct-4 expression maintained cancer stem-like properties in lung cancer-derived CD133-positive cells. PLoS One 2008; 3: e2637.

10. Wu Y, Wu PY. CD133 as a marker for cancer stem cells: progresses and concerns. Stem Cells Dev 2009; 18: 1127-1134.

11. Bao S, Wu Q, McLendon RE, Hao Y, Shi Q, Hjelmeland $A B$ et al. Glioma stem cells promote radioresistance by preferential activation of the DNA damage response. Nature 2006; 444: 756-760.

12. Facchino S, Abdouh M, Chatoo W, Bernier G. BMl1 confers radioresistance to normal and cancerous neural stem cells through recruitment of the DNA damage response machinery. J Neurosci 2010; 30: 10096-10111.

13. Woodward WA, Chen MS, Behbod F, Alfaro MP, Buchholz TA, Rosen JM. WNT/betacatenin mediates radiation resistance of mouse mammary progenitor cells. Proc Natl Acad Sci USA 2007; 104: 618-623

14. Woodward WA, Bristow RG. Radiosensitivity of cancer-initiating cells and normal stem cells (or what the Heisenberg uncertainly principle has to do with biology). Semin Radiat Oncol 2009; 19: 87-95.

15. Howell SB, Safaei R, Larson CA, Sailor MJ. Copper transporters and the cellular pharmacology of the platinum-containing cancer drugs. Mol Pharmacol 2010; 77: 887-894.

16. Moore N, Lyle S. Quiescent, slow-cycling stem cell populations in cancer: a review of the evidence and discussion of significance. J Oncol 2011; 2011: pii: 396076.

17. Tanida S, Mizoshita T, Ozeki K, Tsukamoto H, Kamiya T, Kataoka H et al. Mechanisms of cisplatin-induced apoptosis and of cisplatin sensitivity: potential of bin1 to act as a potent predictor of cisplatin sensitivity in gastric cancer treatment. Int J Surg Oncol 2012; 2012 862879

18. Krejci L, Altmannova V, Spirek M, Zhao X. Homologous recombination and its regulation. Nucleic Acids Res 2012; 40: 5795-5818.

19. Li Y, Laterra J. Cancer stem cells: distinct entities or dynamically regulated phenotypes? Cancer Res 2012; 72: 576-580.

20. Sullivan JP, Minna JD, Shay JW. Evidence for self-renewing lung cancer stem cells and their implications in tumor initiation, progression, and targeted therapy. Cancer Metastasis Rev 2010; 29: 61-72.

21. Jiang F, Qiu Q, Khanna A, Todd NW, Deepak J, Xing L et al. Aldehyde dehydrogenase 1 is a tumor stem cell-associated marker in lung cancer. Mol Cancer Res 2009; 7: 330-338.

22. Meng X, Li M, Wang X, Wang Y, Ma D. Both CD133 + and CD133 - subpopulations of A549 and H446 cells contain cancer-initiating cells. Cancer Sci 2009; 100: 1040-1046.

23. Chiou SH, Wang ML, Chou YT, Chen CJ, Hong CF, Hsieh WJ et al. Coexpression of Oct4 and Nanog enhances malignancy in lung adenocarcinoma by inducing cancer stem celllike properties and epithelial-mesenchymal transdifferentiation. Cancer Res 2010; 70: 10433-10444.

24. Hsu HS, Huang PI, Chang YL, Tzao C, Chen YW, Shih HC et al. Cucurbitacin I inhibits tumorigenic ability and enhances radiochemosensitivity in nonsmall cell lung cancerderived CD133-positive cells. Cancer 2011; 117: 2970-2985.

25. Leung EL, Fiscus RR, Tung JW, Tin VP, Cheng LC, Sihoe AD et al. Non-small cell lung cancer cells expressing CD44 are enriched for stem cell-like properties. PLOS One 5: e14062.

26. Morrison R, Schleicher SM, Sun Y, Niermann KJ, Kim S, Spratt DE et al. Targeting the mechanisms of resistance to chemotherapy and radiotherapy with the cancer stem cell hypothesis. J Oncol 2011; 2011: 941876

27. Piao LS, Hur W, Kim TK, Hong SW, Kim SW, Choi JE et al. CD133 + liver cancer stem cells modulate radioresistance in human hepatocellular carcinoma. Cancer Lett 2012; 315: 129-137.

28. Phillips TM, McBride WH, Pajonk F. The response of CD24(-/low)/CD44 + breast cancer-initiating cells to radiation. J Natl Cancer Inst 2006; 98: 1777-1785.

29. Timerbaev AR, Hartinger CG, Aleksenko SS, Keppler BK. Interactions of antitumor metallodrugs with serum proteins: advances in characterization using modern analytical methodology. Chem Rev 2006; 106: 2224-2248.

30. Frosina G. DNA repair and resistance of gliomas to chemotherapy and radiotherapy. Mol Cancer Res 2009; 7: 989-999.

31. White DE, Negorev D, Peng H, Ivanov AV, Maul GG, Rauscher FJ 3rd. KAP1, a nove substrate for PIKK family members, colocalizes with numerous damage response factors at DNA lesions. Cancer Res 2006; 66: 11594-11599.

32. Bakkenist CJ, Kastan MB. DNA damage activates ATM through intermolecular autophosphorylation and dimer dissociation. Nature 2003; 421: 499-506.

33. Austen B, Powell JE, Alvi A, Edwards I, Hooper L, Starczynski J et al. Mutations in the ATM gene lead to impaired overall and treatment-free survival that is independent of IGVH mutation status in patients with B-CLL. Blood 2005; 106: 3175-3182.

34. Li X, Lin HH, Chen H, Xu X, Shih HM, Ann DK. SUMOylation of the transcriptional corepressor KAP1 is regulated by the serine and threonine phosphatase PP1es. Sci Signal 2010; 3: ra32

35. Yan X, Ma L, Yi D, Yoon JG, Diercks A, Foltz G et al. A CD133-related gene expression signature identifies an aggressive glioblastoma subtype with excessive mutations. Proc Natl Acad Sci USA 2011; 108: 1591-1596.

36. Bergh J, Nilsson K, Ekman R, Giovanella B. Establishment and characterization of cell lines from human small cell and large cell carcinomas of the lung. Acta Pathol Microbiol Immunol Scand A 1985; 93: 133-147.

37. Abate G, Mshana RN, Miorner H. Evaluation of a colorimetric assay based on 3-(4,5dimethylthiazol-2-yl)-2,5-diphenyl tetrazolium bromide (MTT) for rapid detection of rifampicin resistance in Mycobacterium tuberculosis. Int J Tuberc Lung Dis 1998; 2 : $1011-1016$

38. Darzynkiewicz Z, Huang X. Analysis of cellular DNA content by flow cytometry. Curr Protoc Immunol 2004; Chapter 5(Unit 5.7):

39. Gallo D, Fruscella E, Ferlini C, Apollonio P, Mancuso S, Scambia G. Preclinical in vivo activity of a combination gemcitabine/liposomal doxorubicin against cisplatin-resistant human ovarian cancer (A2780/CDDP). Int J Gynecol Cancer 2006; 16: $222-230$.

(c)

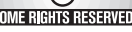
licensed under the Creative Commons Attribution-NonCommercial-No Derivative Works 3.0 Unported License. To view a copy of this license, visit http://creativecommons.org/licenses/by-nc-nd/3.0/ 